\title{
Editorial: Tax policy
}

The UK has just introduced a new tax system for pensions - and it's turning out to be very far from the simplification exercise that was intended. A move from the previous 14 different tax regimes was of course always welcome; but a move from the previous excessively complicated 1,300 pages of law and regulation to 3,500 pages of even more complicated legislation is a curious form of progress. Her Majesty's Revenue and Customs (HMRC) would argue that very little of the legislation applies to 95 per cent of the population; it is intended to cover transitional arrangements and people with earnings over around 100,000 a year (about 5,000 people according to HMRC). If it were not for those factors, the legislation would be simple - and the impact day-to-day on practice is minimal.

If it were true, the price might have been acceptable. The deal offered by the Treasury and HMRC was that a sweeping away of the previous overweening structure would involve the pensions movement in a price. That price was the introduction of a cap on the amount of pensions or pensions worth that any one individual could enjoy. And it seemed to be a price worth paying.

But unfortunately things have not worked out quite as expected. Pensions are not like other financial instruments, or to be accurate they are not financial instruments at all. Pensions are derived from superannuation, a form of defined pay, offered by employers so that their employees can retire without being an embarrassment. The turnover of staff, contrary to popular belief, is not much greater than it used to be forty years ago. And the desire of both employers and employees to provide pensions gives few signs of abating. What is causing difficulties has been an excess of regulation, an imposition of unmanageable risk, and inappropriate tax systems.

Most tax systems round the globe (at least in the developed nations) accept the principle of fiscal neutrality for pre-funded systems. Unfunded systems operate in the same way; in other words an employer pays pensions like he/she pays wages - and both are deductible. The only involvement of the fiscal authorities is to control the amount and extent of pre-funding, a control that in many cases should be otiose. So how did this dysfunctional situation come about? And is there anything we can do to bring back a proportionate and sensible tax system for UK pensions?

There was a general agreement several years ago that the taxation regime applied to pensions in the UK was over-complicated. It had developed over seventy years, based on the principle of exempt, exempt, tax (EET), that pensions, unlike savings, should be accrued tax free and taxed when paid (on the principle of EET). So when the Treasury and the then Inland Revenue agreed to be brave, and look carefully at the National Association of Pension Funds (NAPF)'s paper on simplifying the tax regime, also based on EET, it seemed that progress had been made. 
The former system was clearly unacceptable, both for HMRC and the public. It accommodated fourteen different fiscal regimes, imposed different rules for personal and workplace arrangements, depended on extensive pages of Inland Revenue guidance and updates, with many of the rules being antiquated and without a clear policy purpose behind them. It was accompanied by extensive HMRC discretions, again without an apparent schema underlying the application of discretions. The NAPF paper 'Simplifying Pensions' set out the rationale behind cutting back the thicket of regulation, and rewrote the legislation in under two pages of A4. It was intended to replace 1,300 pages of materials, much of it detailed, prescriptive and containing rules the purpose of which had been forgotten many years before.

Accordingly, a suggestion some years later from the Treasury and HMRC that the pensions movement should consider a new simplified system therefore came as a breath of fresh air. It was largely based on the NAPF's proposals - but added to them by imposing a cap on the amount of pre-funding that could be achieved, with a tax charge on excesses. The HMRC arguments indicated that the limits in any event would affect only a tiny minority, and a rich minority at that, for whom the tax system was already giving disproportionate benefits and who could afford to take a modest hit to their expectations. Despite some initial misgivings, employers, managers, trustees and advisers all saw the chance of a new tax system as a useful opportunity, despite the (unnecessary) constraints.

For reasons which even today are not entirely clear, the simple system was proposed subject to these limits - and the advantages would include a clearing away of the HMRC discretions (thereby reducing the head count at HMRC offices by around 150) a sweeping away of the 1,300 pages of excess regulation (thereby making pension administration that much simpler) and a single taxation regime (thereby making the system better understood by the public, and encouraging further provision). The price, as mentioned, was a limit on the amount of pre-funded pension arrangements. The need for the limit was political rather than financial, but according to the (somewhat suspect) statistics, the new cap only covered about 5,000 people out of a population of 60 million, and, since it saved substantial costs on administration by insurance company and pension funds, not to mention accountants and lawyers, the savings for the movement could be material. In addition, the proposed new system simplified the issues of transfers between personal pension schemes and workplace pensions, and disposed of quantities of technical requirements relating to the types of benefits, the pace of funding, the allocation of surpluses and international arrangements. Indeed when the outline rules emerged it even transpired that the lump sum tax free amount had been increased. So the price, while it seemed high and inappropriate, seemed also not unreasonable.

In April 2006 the implementation of the new system took effect. It is a far cry from the original dream - and the contract between HMRC and the public originally offered. It involves around 200 pages of largely impenetrable primary legislation in the Finance Act 2004, amended by the Finance Act 2005 because of some initial errors, and amended by the Finance Act 2006 because of subsequent concerns. The design brief indicated that there would be no need for either regulations or guidance notes, especially guidance notes, 
because the schema was clear in the primary legislation. There are now around fifteen to twenty sets of regulations, comprising around another 200 pages of highly dense rules. This is supplemented by the semi-guaranteedto-be unnecessary 3,000 pages of guidance notes issued by HMRC in a form on the internet which is all but unusable, and capable of retrospective change without notice. There is no way of knowing whether they have been changed day by day because they are only available on the web, and short of printing and storing a daily copy, it is not possible to track the quasi-legislation. It is backed by a range of draconian and non-discretionary penalties and sanctions for breach of a system which most HMRC officials find difficult to understand.

This is most unsatisfactory. The HMRC and Treasury offer was of simplification, not of 3,500 pages of new law, and high if not excessive amendment costs per scheme which can reach 50,000 and rising. The system is not back even to where it started from in terms of complexity; it is worse.

The changes come at a time when government policy at the highest level is committed to a repeal of unnecessary bureaucracy. The new pensions fiscal system clearly crosses the grain of deregulation announced by both the Chancellor and the Prime Minister in speeches in recent months, and the objectives of better regulation, to which the government is deeply committed. The industry has opened preliminary negotiations with HMRC and the Treasury at the highest level to try to recover the original objectives, to help both government and public. In the meantime the UK pensions industry is being forced to cope with an unsustainable fiscal regime over-loaded with pointless rules and regulations, extra costs, and extra impediments to doing business. This was not how it was supposed to be; the question now is how the dream came to be corrupted.

It is hard to disentangle the story over so many years, but some threads are becoming clear. First the original design of simplicity was corrupted by a deep misunderstanding of how pensions fiscal policy works, and a belief, unsubstantiated by evidence, that the previous arrangements were advantageous to the higher paid, and were expensive for the Treasury generally. In fact pensions are as expensive as are salaries in terms of corporate deductions - but there is no suggestions that higher salaries involve higher costs to the Treasury.

Secondly there was a lack of consistency in the application of policy by the regulators; there was little consensus between Treasury and HMRC, and there was a corrosive mild sense of paranoia about a new system which seemed too simple to be true. In addition there was no one official where the buck stopped; the long chain of command meant that the message became distorted through the system.

And, HMRC would claim, it is the industry's fault for trying to preserve some form of grandfathering of existing arrangements as well as avoiding possible abuses. In fact the one abuse control, the requirement for annuity purchase, was watered down in the new arrangements and these will themselves need amendment in due course.

This awful tale does not bode well for other attempts for reform elsewhere in the fiscal sector. But at the same time it offers lessons which could help the designers of future reforms. It is all such a shame that it is the pensions sector that has to suffer the pain - and the expense - of the learning process, with a consequent reduction in pensions 
provision for those who need it. The other tragedy is that much of the sector will be lost to the UK economy as increasingly those UK-based pension schemes which survive the system explore registering in warmer and more welcoming climes following the opportunities for forum shopping after the European Pensions Directive. In the end it may be that international regulatory and fiscal competition will improve the position for the UK generally; but it might have been better for UK plc if we had not had to explore the opportunities abroad.
Robin Ellison

Editor 